\title{
"Empathize with me, Doctor!” Medical Undergraduates Training Project: Development, Application, Six-months Follow-up
}

\author{
Vasileios N Kiosses ${ }^{1}$, Athina Tatsioni ${ }^{1}$, Ioannis DK Dimoliatis ${ }^{1}$, Thomas Hyphantis ${ }^{1}$ \\ ${ }^{1}$ Medical Faculty, School of Health Sciences, University of Ioannina, Greece. \\ Correspondence: Vasileios Kiosses, Medical Education Unit, Department of Hygiene \& Epidemiology, Medical Faculty, \\ School of Health Sciences, University of Ioannina, 45110 Ioannina, Greece.
}

Received: May 12, 2017

Accepted: June 1, 2017

Online Published: June 2, 2017

doi:10.11114/jets.v5i7.2418

URL: https://doi.org/10.11114/jets.v5i7.2418

\begin{abstract}
The aim of the study was to assess the effectiveness of specially designed, empathy training for medical undergraduates, based on the principles of Person-Centered Approach.

Within the context of the humanistic person-centered patient care, the experiential, 60-hour "Empathize with me, Doctor!" training program contains theory, personal development and skills development. Role plays, experiential exercises, self-awareness exercises, active listening practice and conduction of a person-centered interview constituted the training.

Forty-two medical undergraduates (66\% females; $29 \%$ fourth year of study, $40 \%$ fifth, $31 \%$ sixth) from the University of Ioannina in Greece applied and all of them completed the empathy training. Forty-five medical students comprised a similar according to age and year of studies control group.

The Jefferson Scale of Physician Empathy (JSPE) was used to assess the empathic performance, and Cohen's d to assess the practical importance of any statistical difference.

The JSPE mean score (and standard deviation) before, after and six months follow-up was 109.3(12.7), 121.1(9.0), 121.1(9.5), respectively. The before-after and before-follow-up difference was highly significant (CI95\%, $\mathrm{p}<0.001$ in both cases), and of great practical importance ( $\mathrm{d}=1.072, \mathrm{~d}=1.052$, respectively), while no decrease was observed six-months later (CI 95\%, $\mathrm{p}=0.999, \mathrm{~d}<0.001)$. Control group reached a JSPE 108.7(10.5), similar to intervention group before training $(\mathrm{CI} 95 \%, \mathrm{p}=0.832)$, and highly different and important compared to after $(\mathrm{CI} 95 \% \mathrm{p}<0.001 ; \mathrm{d}=1.268)$ and follow-up (CI 95\%, $\mathrm{p}<0.001 ; \mathrm{d}=1.238)$ intervention scores.
\end{abstract}

The "Empathize with me, Doctor!" improved significantly and importantly medical undergraduates' empathic performance, which was maintained intact for at least six months.

Keywords: empathy, medical education, training, medical students

\section{Introduction}

In modern times, medicine has become over-specialized, in terms of organs and diseases, against patients', their families' and society's needs and concerns. This has led to a lack of attention on other aspects of the disease beyond symptoms. A re-conceptualization of the core mission of medicine became obvious. A disease-centered medicine has been replaced by the person-centered medicine (PCM), introduced by Balint (1969), who emphasized on the physicians' understanding. PCM seeks to promote health as a state of physical, mental, spiritual and social well-being and not only to decrease pain (World Health Organization [WHO], 1946; Sanedal, 2012). It has a significant influence from humanism, where a personalized understanding of the illness is the main context, containing all the psychological and emotional elements of the disease. According to the Institute of Medicine (2001), person-centered care is "care that is respectful and responsive to individual patient preferences, needs and values, and ensuring that patient values guide all clinical decisions" (p. 49). Person-centered medicine's concept in primary care is oriented at "people and populations, rather than pre-defined diseases or interventions as stand-alone issues" (Van Wheel, 2010, p. 337).

Empathy is a crucial component to promote person-centered care. Clinical empathy includes understanding patient's situation, perspective and feelings as well as their attached meanings; and communicating understanding and checking its accuracy (Platt, 1992). It is linked with fewer burnout effects of the healthcare professionals and more accurate 
diagnoses (Anfossi \& Numico, 2004), creates a safe, pleasant and comfortable environment where the patient is facilitated to speak openly (Suchman, Markaki, Bechman \& Frankel, 1997; Fink, Sorensen, Engberg, Holm \& Munk-Jorgensen, 1999) and seems to decrease patients' and doctors' stress (Halpern, 2003). Medical empathy is not that different from Carl Rogers' ( 1951) definition of empathy described in his Person-Centered Approach (PCA): empathy is not a technique but a way of being; empathy is the ability to deeper understand other's frame of reference and involves being able to put yourself in the other's position. In counseling, PCA found wide application in various domains such as psychotherapy (client-centered therapy), education (student-centered learning), organizations, and other group settings.

The term "medical empathy" vindicates significant part in the medical curricula. In the "Learning Outcomes/ Competences for Undergraduate Medical Education in Europe: The Tuning Project (Medicine)", developed by the MEDINE Thematic Network of about 100 European medical schools, empathy is highlighted as a main professional attribute, incorporated in the outcomes for medical professionalism (Cumming \& Ross, 2008). Training programs have been developed in order to educate healthcare professionals in empathy through communication skills trainings with a variety in teaching methods, duration and curriculum (McKinstry, Aschcroff, Car, Freeman \& Sheikh, 2006; Moore, Wilkinson \& Mercado, 2004). A systematic review of the literature revealed that educational programs could enhance empathic performance among medical students with a statistical significant increase (Bat- Rawden, Chilsom, Anton \& Flickinger, 2013) but with a relatively low mean effect size (0.23), while the heterogeneity in the design of the studies included was an inhibiting factor in extracting safe conclusions. The efficacy of communication skills training courses in oncology was assessed by another systematic review which revealed a moderate effect of the training on communication performance (Barth \& Lannen, 2011). In the current research, we combined the framework of the Person-Centered Approach (PCA) within medical education, in order to develop and design experiential empathy training for medical undergraduates. The "Empathize with me, Doctor!" project (EwMD) was developed and applied. Is EwMD successfully applied within medical school to enhance medical undergraduates' empathic performance? Does the effect of a PCA-based empathy training maintain?

\section{Method}

\subsection{Participants}

Medical undergraduates at the University of Ioannina, Ioannina, Greece, were voluntarily participated in the "Empathize with me, Doctor!" project for training in empathy. None of them had ever participated in any empathy training before. The "Empathize with me, Doctor!" training was offered during the elective course "Empathy during doctor-patient relationship" in the Medical School, University of Ioannina, Ioannina, Greece. Trainees had to participate at least in the $90 \%$ of the total training (52 of the 60 hours) to be qualified and to be a part of the study. Only students in the $4^{\text {th }}$ year of their studies and beyond could apply, since at this year they visit university hospital clinics and hence they interact with patients.

In order to avoid contamination from the intervention group, a control group of undergraduate volunteers of the same year of study from two different medical schools (Aristotle University of Thessaloniki, Thessaloniki, Greece; Democritus University of Thrace, Alexandroupolis, Greece) was asked to answer the same questionnaire. They received no empathy training at all by us or anybody else.

The study was conducted as a part of the elective course "Empathy during doctor-patient relationship" approved by the Studies' Committee, from the Medical School, University of Ioannina, Ioannina, hence an ethical approval was not required.

\subsection{The "Empathize with me, Doctor!" (EwMD) Training Project: Development and Application}

The EwMD project was a small group experiential training, lasted 60 hours distributed in three 20-hour workshops four weeks apart from each other, including theory, personal development, and skills development. Due to the experiential nature of the training, theory and practice were interwoven and not separated during the training process.

The theoretical part of the training included introduction to communication skills (non-verbal communication, verbal communication, therapeutic guidelines, appropriate use of touch), introduction to the Person-Centered Approach combined with the basic principles of the Person Centered medicine, and medical history taking in a person-centered way, emphasizing on how to ask for symptoms and how to use open and close questions. Furthermore the clarification of what empathy is in terms of counseling constituted a large part of the training. Also, medical undergraduates were introduced to theory of bereavement in a medical context, and how to break bad news empathetically.

Since it is very important, when someone is trying to be empathic, to be congruent and aware of his/her own needs and boundaries during encounters with patients, a personal development section, including experiential exercises and encounter groups, was added. Creative arts were used as tools to facilitate medical undergraduates to introspect and hear 
their inner needs. Encounter groups were used to emphasize verbal interaction.

The skills development section contained active listening exercises, role plays, non-verbal communication games, case studies, conduction of a person-centered interview and practical implications of empathy.

This training had a clear aim, to give the chance to the members of the group to be empathic in relation with the other members and then try to be empathic during encounters with patients. For this interaction an experiential approach to learning was necessary. Trainees were not introduced to specific techniques. This would be in opposition to the theory of the PCA. Trainees were introduced on how to be congruent, genuine and respectful during their encounters with the patients.

Two instructors, trained in Person-Centered Approach, facilitated the training. Trainers tried to create a space of acceptance, genuineness and empathy without judgment, in order to help trainees to try new ways of interacting and relating.

\subsection{Assessment}

In order to measure differences in students' empathic performance before and after training, we used the Jefferson Scale of Physician Empathy (JSPE), a validated and reliable (Cronbach alpha $=0.78$ ) questionnaire, comprising 20 items such as "I try to imagine myself in my patients' shoes when providing care to them", "Empathy is a therapeutic skill without which my success as a health care provider would be limited" (Hojat et al., 2001). The questionnaire can be answered in a 1-to-7 point Likert scale from strongly disagree to strongly agree. Scores are ranged from 20 (worst) to 140 (best), with higher scores indicating better empathy performance. We used the translated in Greek and validated version (Ouzouni \& Nakakis, 2012).

We need to highlight the fact that the midpoint of the Likert scale is neutral (neither agree- nor disagree), as developed by the original JSPE. In order to avoid the risk of a single line of midpoint responses, we will exclude from the results all the questionnaires including more than $3 / 4$ of midpoint answers.

All trainees had a seven-day deadline before the first and after the last day of the training, to complete anonymously the JSPE and assess their empathy competence. Six months after the completion of the training, there was a follow up measurement. In order to compare results in an individual basis (paired tests) without violating anonymity, each trainee created a personal code known exclusively to them, used in every completion of the questionnaire.

JSPE mean score and standard deviation $(S D)$ were calculated for the control and before, after, and six months later for the intervention group. One sample paired t-test was used to assess the difference within group, and two samples unpaired t-test to assess difference between intervention and control groups. Effect size was calculated to judge the practical importance of the findings, using Cohen's $d$

$$
d=\frac{2 t}{\sqrt{(d f)}}
$$

where $t=t$-test and $d f=$ degrees of freedom. Cohen's $d$ is interpreted as a small effect size if $d<0.2$, medium effect size if $0.2 \leq d \leq 0.5$, and large effect size if $d>0.5$ (Cohen, 1988). The SPSS (v.18) software was used.

\section{Results}

\subsection{Participants}

During three consecutive semesters, spring 2014, winter 2014 and spring 2015, forty-two medical undergraduates successfully completed the full (no absence) empathy training as designed.

Table 1. Participants in the study. Control and intervention groups and their comparison according to year of study, gender, and age

\begin{tabular}{llll}
\hline & Control group & Intervention group & $\begin{array}{l}\text { Test } \\
\boldsymbol{p} \text {-value }\end{array}$ \\
\hline TOTAL & 45 & 42 & \\
SEMESTER & & & \\
$\quad$ Spring 2014 & & 12 & \\
$\quad$ Winter 2014 & & 14 & \\
$\quad$ Spring 2015 & 45 & 16 & \\
YEAR OF STUDY & & & $X^{2}=1.690$ \\
$4^{\text {th }}$ & 10 & 12 & $p=0.430$ \\
$5^{\text {th }}$ & 15 & 17 & \\
$6^{\text {th }}+$ & 20 & 13 & $X^{2}=0.024$ \\
GENDER & & & $p=0.878$ \\
$\quad$ Male & 15 & 15 & $t=3.972$ \\
Female & 30 & 28 & $p=0.000149$ \\
AGE & & & \\
$\quad$ Range (min $-\max )$ & $21-25$ & $21-28$ & \\
Mean (SD) & $22.2(0.97)$ & $23.3(1.49)$ & \\
& & & \\
\hline
\end{tabular}


During the spring 2015 semester, 45 undergraduates participated in the control group, with no difference compared to intervention group according to gender $(p=0.878)$ and year of study $(p=0.43)$, while the mean age of the control group was one year smaller than that of the intervention group, 22.2 versus $23.3(p<0.001)$.

\subsection{Comparisons within and between Groups}

All forty-two medical undergraduates of the intervention group completed the JSPE before and after the training and six months later. Furthermore, all answers were included in the statistical analysis. Only one participant completed 7/20 midpoint answers and the rest of them had fewer midpoint answers during all assessments. Hence, none of the participants met the exclusion criteria. The mean score (and standard deviation) before, after, and six months later was 109.3 (12.7), 121.1 (9.0), and 121.1 (9.5) respectively. The before and after difference was highly significant $(p<0.001)$, as well as the before and six months later $(p<0.001)$, with no any mean score decrease between after and six-month follow-up $(p=0.999)$. The effect size was very large for the before-after and before-follow-up assessment (Cohen's $d$ 1.072 and 1.052, respectively), while extremely low effect size between after and follow-up was observed $(d<0.01)$.

Table 2. Comparisons between control and intervention groups and between before, after and follow-up within the intervention group; two tailed t-test (t) ${ }^{1}$ with CI $95 \%$ and corresponding exact p-value (p), and Cohen's d

\begin{tabular}{lllll}
\hline & & Before & After & Follow-up \\
\hline \multirow{3}{*}{ Control } & $t$ & 0.258 & 5.882 & 5.761 \\
& $p$ & 0.797 & $8 \times 10^{-7}$ & $13 \times 10^{-6}$ \\
& $d$ & 0.051 & 1.268 & 1.238 \\
Before & $t$ & & 6.521 & 6.730 \\
& $p$ & & $1 \times 10^{-7}$ & $2 \times 10^{-8}$ \\
& $d$ & & 1.072 & 1.052 \\
After & $t$ & & & 0.000 \\
& $p$ & & & 0.999 \\
& $d$ & & & 0.000 \\
\hline
\end{tabular}

The mean score for the control group was 108.7 (10.5). There was no difference with the intervention group before training $(p=0.797)$, but very high difference after $(p<0.001)$ and six-month follow-up $(p<0.001)$. Accordingly, there was very low effect size for the control group versus the intervention group before the training (Cohen's $d=0.051$ ), while large effect size observed for the controls versus after $(d=1.268)$ and follow-up $(d=1.238)$.

\section{Discussion}

Forty two medical undergraduates completed successfully the Empathize with me, Doctor! (EwMD) training, a specially designed program to train students in empathy and sensitize them to promote person-centered care. The assessment was held through the 20-item JSPE and the before-after highly significant and practically very important difference remained unchanged 6-months later.

Most training programs include empathy as a part of communication skills training. The difference between communication skills training and the EwMD project is that the second aims specifically on empathy and how it can be promoted. Communication skills were only an introductory part of the EwMD training. EwMD effect size was over five times the effect size of an updated systematic review and meta-analysis of interventions promoting empathy to medical students (Batt- Rawden, Chilsom, Anton \& Flickinger, 2013) including 18 articles of which only 1 was empathy-focused $(1.268 / 0.23=5.5)$. The overall mean effect size of the trainings included was 0.23 , low, considering weak practical importance of the interventions In addition the effect size of the only empathy-focused intervention was $\mathrm{d}=0.45$, which indicates moderate practical importance. To avoid diminution of the empathy during time, it is important that medical undergraduates and physicians continue to practice. According to a systematic review of the literature (Neumann et al., 2011) empathy declines during medical school years. In contrast, the impact of the EwMD project remained unchanged six months after the completion of the training, both statistically and practically. The strong statistically significant impact of this EwMD project may be correlated with the experiential nature of the training, containing role plays, feedback and small group discussions which are the best strategies within such intervention programs (Berkhoff, van Rijssen, Schellart, Anema \& van der Beek, 2010). The EwMD project is learner-centered including practicing skills, which is shown to be the most effective teaching approach in improving communication skills (Berkhoff, van Rijssen, Schellart, Anema \& van der Beek, 2010).

Other medical and health care schools have included educational interventions to maintain and enhance empathy in undergraduate students or health care professionals (Bayne, 2011; Bunn \& Terpstra, 2009; Dikici, Yaris \& Cubukcu, 2009; Dow, Leong, Anderson \& Wenzel, 2007; Fine \& Therrien, 1977; Ghetti, Chang \& Gosman, 2009; Kushner, Zeiss,

\footnotetext{
${ }^{1}$ Unpaired $t$-tests with 85 degrees of freedom in all comparisons with the control group; paired $t$-tests with 41 degrees of freedom otherwise.
} 
Feinglass \& Yelen, 2014; Neumann et al., 2009). However, to the best of our knowledge, only the EwMD project included a personal development section, and perhaps this explains the strong effect size. Through experiential exercises, the training facilitated self-awareness in relation with a whole new perspective in relating and hence the experiential nature of the training became stronger. Another component which makes the EwMD project powerful is the person-centeredness of the training and the fact that the training embraces the three core conditions of the Person-Centered Approach (empathy, unconditional positive regard, and congruence). Through the EwMD training the physician facilitates the patient to express and experience the emotional context that coexists with the suffering. The difference between the EwMD and other empathy trainings is that, in the EwMD, empathy is not standing alone. In the context of the EwMD, empathy, unconditional positive regard, and congruence are inseparable and there is an interrelationship between them. As stated by Wilkins (2000) within the Person-Centered Approach "empathy and congruence provide a framework in which unconditional positive regard is believable, but it is also because it is impossible to be truly accepting of another without being open to one's own inner experience and being in a personal state of harmony." Even though specific interventions were developed in order to enhance physicians' and medical students' empathic performance, the term empathy is lacking a widely accepted definition. In the current study, authors adopt the PCA and embrace the definition of empathy within this frame.

It is worth noting that the high scores during the first measurement, before any training, impressed the authors of this paper. Between controls and before measurement versus after and follow up measurement there is a difference of 11.9 Jefferson units (after $=$ follow-up $=121.1$ minus before $=109.3$ ) in the JSPE scale from 20 to 140. After controlling for the 1-to-L bias (Dimoliatis \& Gelastopulu, 2013), these scores become: control $=73.9 \%$, before $=74.4 \%$, after $=$ follow up $=84.25 \%$ in the standard 0-100 scale. Accordingly, the 11.9 JSPE units, become $84.25 \%$ minus $74.4 \%=9.85 \%$, approximately $10 \%$ in the standard 0-100 scale. The impressive thing was not this "only 10\%" empathy improvement, but the without any empathy training so high JSPE score $74.4 \%$, three over four. Due to no previous empathy training in the school and students' ignorance of what empathy actually is and how it can be promoted, lower scores in the before self-assessment were expected. Authors suppose that this high rating before the training occurred either because of a possible weakness of the JSPE to measure the exact empathy level or because of the possible inability of the trainees to assess themselves accurately (or both). Authors are currently working on a method to clarify this problem. Furthermore, although trainees scored high in the before measurement, they were hesitating to rate themselves much higher in the after measurement. During the after (and follow up) scoring, perhaps undergraduates were more aware about the difficulty in performing empathetically; thus, possibly their scores were more accurate, if not hesitant. It is also noteworthy that most of the trainees who completed the EwMD were female. The current literature interprets this finding stating that women tend to develop more caregiving attitudes (Hojat et al., 2002) and research has shown that female physicians contribute to a better empathic relationship with their patients (Eisenberg \& Lennon, 1983). However, more women also comprised our control group as well (no difference, $\mathrm{p}=0.878$ ). Thus, the EwMD effectiveness is not related to gender.

Small group teaching is EwMD's prerequisite, in order for the members to interact sufficiently. "The assumption in these groups is similar to that of person-centered therapy: the individual will grow in a positive way by resisting social restrictions and by interacting with others honestly and openly" (Yalom, 2005, p. 608). One could argue that the relatively small sample would render a limitation of the study if we take into consideration that potentially participants were sensitized in enhancing their interaction with their patients, and this would be a significant reason of their high JSPE scores before training and empathic improvement after the training. However, the control group was equally sensitized (no difference with the intervention group before any training) and, even if participants were more sensitized comparing to non-participants, the EwMD training succeeded to increase significantly and importantly their empathy. Furthermore, the intervention group was in average one year older than the control group (23.3 vs. 22.2), due to that some older students participated in the first group. Though the difference is statistically significant, we do not think it is that important, especially since there was no difference according to year of study and gender. Although this point needs further clarification, we continue believing that our conclusions would remain the same. Furthermore, the fact that the control groups is drawn from different medical schools, there is no way to know how similar or not the students' experiences are in the various places, although we need to highlight that medical curricula among are not differ significantly.

Additionally, the JSPE measures self-perceptions of medical undergraduates about their empathic performance, not the performance itself. Possibly a measurement tool that assesses objectively the empathic performance would be more accurate. Using the only available tool for all measurements (controls, before, after, 6-months), is a good indicate that EwMD is an effective training procedure, increasing real empathy performance, not simply trainee perceptions.

Medical students and health care professionals in general would benefit by long term support in empathy and relevant skills. This could be part of their clinical supervision as understood by counseling. It would be of interest for future 
research to assess the effect of a long term support and supervision. The effect of the EwMD remained immutable six months after the completion of the training. We believe that this is a good indication that EwMD's impact will remain high 12 or 24 months later; this is a future project. It would also be interesting for future search to overcome the limitation of the lack of participants' randomization.

\section{Conclusion}

The "Empathize with me, Doctor!" project significantly, statistically and especially practically (clinically), enhanced medical undergraduates' empathic performance, which six months later remained unchanged, according to trainees' perceptions. The combination of the experiential learning with the personal development section, during the training, creates a forceful empathic enhancement. The effects of the training are of highly practical importance as well. Empathy is cornerstone in the PCA and EwMD, based on PCA approach, embraces the three core conditions of the PCA (empathy, unconditional positive regard, and congruence) and reveals that the application of PCA in the medical context is linked with strong results. The lack of randomization in both intervention and control group would render a limitation of the study, as well as the fact that the effect of the EwMD training was assessed only through self-assessed questionnaire and authors did not assess the impact on patients' outcomes. The EwMD project is, to our knowledge, the first training containing trainees' personal development section and meets the criteria of the Person-Centered Care.

\section{Acknowledgements}

We thank Dr Evangelia Ntzani, Assistant Professor in the University of Ioannina, Department of Hygiene and Epidemiology, Medical School for discussing on the statistical analyses. We also thank Mrs Konstantina Symeonidou and Mrs Carolina Alexiou, Counseling Unit, University of Strathclyde on co-facilitating the training program.

\section{References}

Anfossi, M., \& Numico, G. (2004). Empathy in the doctor-patient relationship. Journal of Clinical Oncology, 22(11), 2258-2259. https://doi.org/10.1200/JCO.2004.99.302

Balint, E. (1969). The possibilities of patient-centered medicine. Journal Royal College of General Practitioners, 17(82), 269-276.

Barth, J., \& Lannen, P. (2011). Efficacy of communication skills training courses in oncology: a systematic review and meta-analysis. Annals of Oncology, 22(5),1030-1040. https://doi.org/10.1093/annonc/mdq441

Batt-Rawden, S. A., Chilsom, M. S., Anton, B., \& Flickinger, T. E. (2013). Teaching empathy to medical students: An updated, systematic review. Academic Medicine, 88(8), 1171-1177. https://doi.org/10.1097/ACM.0b013e318299f3e3

Bayne, H. B. (2011). Training medical students in empathic communication. Journal of Specialists in Group Work, 36, 316-329. https://doi.org/10.1080/01933922.2011.613899

Berkhoff, M., van Rijssen, J., Schellart, A. J. M., Anema, J. R., \& van der Beek, A. J. (2010). Effective training strategies for teaching communication skills to physicians: an overview of systematic reviews. Patient Education and Counseling, 84(2), 152-162. https://doi.org/10.1016/j.pec.2010.06.010

Bunn, W., \& Terpstra, J. (2009). Cultivating empathy for the mentally ill using simulated auditory hallucinations. Academic Psychiatry, 33, 457-460. https://doi.org/10.1176/appi.ap.33.6.457

Cohen, J. (1988). Statistical power analysis for the behavioral sciences (2nd ed.). Hillsdale NJ: Lawrence Earlbaum Associates.

Cumming, A. D., \& Ross, M. T. (2008). The Tuning Project (medicine)-learning outcomes/competences for undergraduate medical education in Europe. Edinburgh: The University of Edinburgh.

Dikici, M. F., Yaris, F., \& Cubukcu, M. (2009). Teaching medical students how to break bad news: a Turkish experience. Journal of Cancer Education, 24, 246-248. https://doi.org/10.1080/08858190902972814

Dimoliatis, I. D., \& Jelastopulu, E. (2013). Surgical operating room measures STEEM/ OREEM overestimate educational environment: the 1-to-L bias. Universal Journal of Educational Research, 1(3), 247-254.

Dow, A. W., Leong, D., Anderson, A., \& Wenzel, R. P. (2007). Using theater to teach clinical empathy: a pilot study. Journal of General Internal Medicine, 22, 1114-1118. https://doi.org/10.1007/s11606-007-0224-2

Eisenberg, N., \& Lennon, R. (1983). Sex differences in empathy and related capacities. Psychological Bulletin, 94, 100-131. https://doi.org/10.1037/0033-2909.94.1.100

Fine, V. K., \& Therrien, M. E. (1977). Empathy in the doctor-patient relationship: skill training for medical students. Journal of Medical Education, 52, 752-757. https://doi.org/10.1097/00001888-197709000-00005 
Fink, P., Sorensen, L., Engberg, M., Holm, M., \& Munk-Jorgensen, P. (1999). Somatization in primary care. Prevalence, health care utilization, and general practitioner recognition. Psychosomatics, 40(4), 330-338. https://doi.org/10.1016/S0033-3182(99)71228-4

Ghetti, C., Chang, J., \& Gosman, G. (2009). Burnout, psychological skills, and empathy: balint training in obstetrics and gynecology residents. Journal of Graduate Medical Education, 1, 231-235. https://doi.org/10.4300/JGME-D-09-00049.1

Halpern, J. (2003). What is clinical empathy? Journal of General Internal Medicine, 18(8), 670-674. https://doi.org/10.1046/j.1525-1497.2003.21017.x

Hojat, M., Gonella, J. S., Mangione, S., Nasca, T. J., Veloski, J. J., Erdmann, J. B. ..., Magee, M. (2002). Empathy in medical students as related to academic performance, clinical competence and gender. Medical Education, 36(6), 522-527. https://doi.org/10.1046/j.1365-2923.2002.01234.x

Hojat, M., Mangione, S., Nasca, T. J., Cohen, M. J. M., Gonella, J., Erdmann, J. B., .. Magee, M. (2001). The Jefferson scale of physician empathy: development and preliminary psychometric data. Education and Psychological Measurement, 61(2), 349-365. https://doi.org/10.1177/00131640121971158

Institute of Medicine. (2001). Crossing the quality chasm. Washington, DC: National Academies Press.

Kushner, R. F., Zeiss, D. M., Feinglass, J. M., \& Yelen, M. (2014). An obesity educational intervention for medical students addressing weight bias and communication skills using standardized patients. BMC Medical Education, 14, 53. https://doi.org/10.1186/1472-6920-14-53

McKinstrey, B., Aschcroff, R. E., Car, J., Freeman, G. K., \& Sheikh, A. (2006). Interventions for improving patients' trust in doctors and group of doctors. Cochrane Database of Systematic Reviews, 3, CD004134. https://doi.org/10.1002/14651858.cd004134.pub2

Moore, P. H., Wilkinson, S. S. M., \& Rivera, M. S. (2004). Communication skills training for health care professionals working with cancer patients. Cochrane Database of Systematic Reviews, 2, CD003751. https://doi.org/10.1002/14651858.CD003751.pub2

Neumann, M., Edelhauser, F., Tauschel, D., Fischer, M., Wirtz, M., Woopen, C., ... Scheffer, C. (2011). Empathy decline and its reasons: A systematic review of studies with medical students and residents. Academic Medicine, 86, 996-1009. https://doi.org/10.1097/ACM.0b013e318221e615

Ouzouni, C., \& Nakakis, K. (2012). An exploratory study of student nurses' empathy. Health Science Journal, 6(3), 534-552.

Platt, F. W. (1992). Empathy: can it be taught? Annals of Internal Medicine, 117(8), 700. https://doi.org/10.7326/0003-4819-117-8-700_2

Rogers, C. (1951). Client-centered Therapy: Its Current Practice, Implications and Theory. London: Constable.

Snaedal, J. (2012). Person Centered Medicine. World Medical \& Health Policy, 4(2), 1-14.

Suchman, A. L., Markakis, K., Beckman, H. B., \& Frankel, R. (1997). A model of empathic communication in the medical interview. Journal of American Medical Association, 277(8), 678-682. https://doi.org/10.1001/jama.1997.03540320082047

Van Weel, C. (2010). Person- Centered medicine in the context of primary care: a view from the World Organization of Family Doctors (WONCA). Journal of Evaluation in Clinical Practice, 2, 337-338.

Wilkins, P. (2000). Unconditional positive regard reconsidered. British Journal of Guidance \& Counseling, 28(1), 23-35. https://doi.org/10.1080/030698800109592

World Health Organization. (1946). Preamble to the Constitution of the World Health Organization as adopted by the International Health Conference, New York, 19-22 June, 1946; signed on 22 July 1946 by the representatives of 61 States (Official Records of the World Health Organization, no. 2, p. 100) and entered into force on 7 April 1948.

Yalom, I. (2005). The theory and practice of group psychotherapy (5th ed). New York: Basic Books. 
Jefferson Scale Physician Empathy (JSPE) score for each student of the both groups before, after, and in 6 months follow-up. Score means and standard deviations (last line) ${ }^{2}$.

\begin{tabular}{|c|c|c|c|c|c|}
\hline \multicolumn{2}{|c|}{ Control group } & \multicolumn{4}{|c|}{ Intervention group } \\
\hline \multirow{2}{*}{ Student } & \multirow{2}{*}{$\begin{array}{l}\text { JSPE } \\
\text { score }\end{array}$} & \multirow{2}{*}{ Student } & \multicolumn{3}{|c|}{ JSPE score } \\
\hline & & & Before & After & Follow-up \\
\hline c1 & 87 & i1 & 77 & 121 & 122 \\
\hline c2 & 89 & i2 & 87 & 95 & 91 \\
\hline c3 & 92 & i3 & 91 & 106 & 106 \\
\hline c4 & 94 & i4 & 91 & 109 & 115 \\
\hline c5 & 97 & i5 & 93 & 122 & 121 \\
\hline c6 & 98 & i6 & 93 & 123 & 124 \\
\hline c7 & 98 & i7 & 96 & 120 & 118 \\
\hline c8 & 99 & i8 & 96 & 125 & 124 \\
\hline c9 & 99 & i9 & 99 & 102 & 109 \\
\hline c10 & 100 & i10 & 100 & 115 & 113 \\
\hline c11 & 101 & i11 & 100 & 132 & 111 \\
\hline c12 & 102 & i12 & 101 & 112 & 115 \\
\hline c13 & 103 & i13 & 101 & 115 & 118 \\
\hline c14 & 104 & i14 & 102 & 107 & 109 \\
\hline c15 & 104 & i15 & 103 & 128 & 116 \\
\hline c16 & 104 & i16 & 104 & 124 & 130 \\
\hline c17 & 106 & i17 & 106 & 110 & 109 \\
\hline c18 & 107 & i18 & 106 & 121 & 115 \\
\hline c19 & 107 & i19 & 107 & 117 & 117 \\
\hline c20 & 107 & i20 & 107 & 125 & 122 \\
\hline c21 & 108 & i21 & 109 & 112 & 121 \\
\hline c22 & 108 & i22 & 111 & 119 & 114 \\
\hline c23 & 108 & i23 & 114 & 116 & 126 \\
\hline c24 & 108 & i24 & 114 & 120 & 131 \\
\hline c25 & 108 & i25 & 115 & 128 & 126 \\
\hline c26 & 110 & i26 & 115 & 132 & 127 \\
\hline c27 & 110 & i27 & 117 & 118 & 117 \\
\hline c28 & 111 & i28 & 117 & 123 & 121 \\
\hline c29 & 111 & i29 & 118 & 127 & 122 \\
\hline c30 & 113 & i30 & 119 & 120 & 117 \\
\hline c31 & 113 & i31 & 119 & 122 & 121 \\
\hline c32 & 114 & i32 & 119 & 132 & 138 \\
\hline c33 & 114 & i33 & 120 & 129 & 121 \\
\hline c34 & 114 & i34 & 122 & 125 & 134 \\
\hline c35 & 114 & i35 & 123 & 124 & 134 \\
\hline c36 & 115 & i36 & 124 & 125 & 123 \\
\hline c37 & 116 & i37 & 124 & 125 & 125 \\
\hline c38 & 117 & i38 & 125 & 130 & 131 \\
\hline c39 & 118 & i39 & 125 & 131 & 128 \\
\hline c40 & 120 & i40 & 125 & 139 & 138 \\
\hline c41 & 122 & i41 & 128 & 131 & 139 \\
\hline c42 & 123 & i42 & 129 & 129 & 127 \\
\hline c43 & 130 & & & & \\
\hline c44 & 133 & & & & \\
\hline c45 & 135 & & & & \\
\hline Mean & 108.7 & Mean & 109.3 & 121.1 & 121.1 \\
\hline$(S D)$ & $(10.5)$ & $(S D)$ & (12.7) & (9.0) & $(9.5)$ \\
\hline
\end{tabular}

\section{Copyrights}

Copyright for this article is retained by the author(s), with first publication rights granted to the journal.

This is an open-access article distributed under the terms and conditions of the Creative Commons Attribution license which permits unrestricted use, distribution, and reproduction in any medium, provided the original work is properly cited.

\footnotetext{
${ }^{2}$ Jefferson Scale Physician Empathy (JSPE) score for each student of the control group (c1 to c45, sorted from smallest to largest) and for each student of the intervention group before, after, and in 6 months follow-up (i1 to i42, sorted from smallest to largest by before, then by after, then by follow-up). Score means and standard deviations (last line).
} 